\title{
Chemically reacting Carreau fluid in a suspension of convective conditions over three geometries with Cattaneo-Christov heat flux model
}

\author{
Chakravarthula Siva Krishnam Raju ${ }^{1}$, Naramgari. Sandeep ${ }^{1}$, Giulio Lorenzini2 ${ }^{2 *}$, Mohammad Hossein Ahmadi ${ }^{3}$ \\ ${ }^{1}$ Department of Mathematics, VIT University, Vellore 632014, India \\ ${ }^{2}$ Department of Engineering and Architecture, University of Parma, Parco Area Delle Scienze 181/A, Parma 43124, Italy \\ ${ }^{3}$ Faculty of Mechanical Engineering, Shahrood University of Technology, Shahrood, Iran
}

\section{Corresponding Author Email: giulio.lorenzini@unipr.it}

https://doi.org/10.18280/mmep.050404

Received: 21 May 2018

Accepted: 3 December 2018

\section{Keywords:}

MHD, Carreau fluid, Cattaneo-Christov heat flux model, Brownian motion and thermophoresis effects, chemical reaction, Biot number, cone, wedgelplate

\begin{abstract}
In this picture, we explored the chemically reacting radiative nanofluid flow over three geometries (plate or wedge and cone) in the presence of Cattaneo-Christov heat flux model. In this we used slip type of Buongiorno nanofluid model used. Numerical solutions are displayed with help of graphs and tables. In addition, the systems of nonlinear ordinary differential equations (ODEs) are solved by using the Runge-Kutta Feldberg method (RKFM). We also validated the current results and found a satisfactory agreement. We presented results for the flow over a wedge, cone and plate cases. We perceived that the thermal, momentum and concentration boundary layers are non-uniform for these three cases. For manufacturing needs, we analyzed the heat and mass transfer rates of the wedge, cone and plate cases and found that due to the dominance of buoyancy force the local Nusselt number is high in flow over cone when compared with the plate and wedge case. From this result we can realize that for heat enhancement processes the cone shaped particles are very helpful when compared with other plate and wedge.
\end{abstract}

\section{INTRODUCTION}

The Fourier's law heat flux model can be modified by adding the relaxation time for flux. It allows the transportation of heat over a propagation of thermal wave with finite velocity. Such types of heat flux model have exciting practical applications such as controlling heating transport systems, solar plant systems and biomedical applications etc. Owing view into this significance initially Cattaneo [1] proposed a heat flux model. Later on, Christov [2] modified the time derivative in Maxwell-Cattaneo's model with material invariant formulation. This can be treated as Cattaneo-Christov heat flux model. The solutions and uniqueness of Cattaneo-Christov equation was demonstrated by Ciarletta and Straughan [3]. Han et al. [4] discussed the viscoelastic fluid due to stretching surface with existence of Cattaneo-Christov heat flux. Hayat et al. [5] examined the magnetohydrodynamic Oldroyd-B fluid flow over a stretching surface in the presence of Cattaneo-Christov heat flux and homogeneous-heterogeneous reactions and decided that the thermal relaxation reduces the temperature field. Rubab and Mustafa [6] extended the Hayat et al. [5] work considering the three-dimensional flow with Maxwell fluid over a stretching surface. Later on, Hayat et al. [7] extended the work for slendering stretching sheet. A numerical analysis of Williamson fluid over a variable thickness sheet was examined by Salahuddin et al. [8].

The mixed convective mass and heat transmission over a plate or wedge has vital role in the process of thermal as well as concentration distribution systems such as extrusion of aerodynamics plastic sheets, continuous automatic casting, crystal growing, heat exchanger, hot rolling, and filament extrusion from a dye, wire drawing and nuclear reactor adjusting mechanisms. In recent days, the flow past a cone also has significance in many real time applications such as industrial, engineering and healthcare safety management systems applications like aeronautical engineering, geosciences, Homeo-therapy treatment, scanning, hydrology, development of electronic chips, astrophysics, solar collectors, endoscopy, dental applications, radiology treatment, lubricating grease for seals and valves etc. Viewing into this initially started the flow over a wedge and cone in 1990's the authors Vajravelu and Nayfeh [9]. Yu et al. [10] examined the constant wall and heat flux on forced convection flow over a rotating wedge and cone by using finite difference approach. Hydrodynamic convection flow over a wedge and cone filled non-Darcy porous layer is discussed by Chamkha [11] and highlighted that the heat source or sink is dominating the temperature profiles. AlHarbi [12] extended this by choosing the variable viscidness and radiation with numerically. With this they decided that thermal radiation improves the temperature and velocity fields. The forced conduction and convection analysis due to rotating cone and wedges was studied by Press [13]. Rushikumar and Shivaraj [14] initiated the magnetohydrodynamic viscoelastic fluid due toplate and conefilled with variable viscosity and highlighted that the thermal dispersion effects are encouraged the heat transfer profiles. Recently, Raju and Sandeep [15] discussed the cross diffusion on magnetohydrodynamic Casson fluid over a rotating cone/plate filled with microorganism and they concluded that rotation have tendency to control the flow. The flow of Casson fluid past a horizontal plate and cone with time and space dependent heat source/sink was 
investigated by Mythili and Sivaraj [16]. Srinivasacharya et al. [17] considered the mixed convection on flow over a permeable wavy surface with variable properties. The crossdiffusion on Falkner-Skan Carreau fluid over a wedge was studied by Raju and Sandeep [18] and highlighted that cross diffusion control the mass transfer profiles. Rashad et al. [19] and Nadeem and Saleem [20] discussed the heat and mass transfer flow characteristics of over cone and rotating cone respectively. Rashidi et al. [21] depicted the homotopy analysis of non-Newtonian fluid past a non-isothermal wedge. Raju and Sandeep [22] considered the magnetohydrodynamic Falkner-Skan Casson fluid due to wedge. Chemically reacting convection flow over accelerating plate with heat generation was illustrated by Hussain et al. [23]. Rashidi et al. [24] studied the magnetohydrodynamic viscoelastic fluid flow properties due to porous wedge with mixed convection. The mixed convection with different flow parameters and geometries was discussed by Gargoosi et al. [25], Aziz [26] and Gargoosi et al. [27]. In this they decided that convective conditions have propensity to improve the mass and heat transfer profiles. Beg et al. [28] considered the slip effect on mixed convective flow with thermally radiated sheet. Heat and mass transfer characteristics of chemically reacting flow over a horizontal stretching sheet by using the differential transform method was explored by Rashidi et al. [29].

All the above mentioned studies focused on the flow over a wedge or cone and cone or plate in the presence of chemical reaction, magnetic field and radiation. But no studies have been described yet up to the author's knowledge Cattaneo-Christov heat flux model for chemically reacting radiative nanofluid flow over a cone or plate or wedge. We presented solutions for the flow over a cone, plate and wedge cases. We saw that the velocity, temperature and concentration boundary layers are non-uniform for these three cases. For manufacturing requirements, we studied the heat and mass transfer rates of the flow over a plate, cone and wedge cases and found that for improving heat transfer rate cone shaped particles are very useful.

\section{MATHEMATICAL FORMULATION}
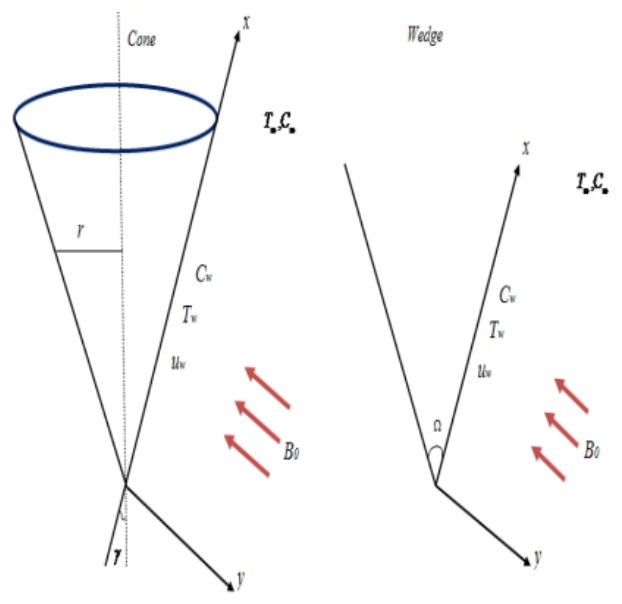

Plate

Figure 1. Physical configuration of the problem

$\mathrm{T}$ Consider a steady, incompressible, free convection laminar flow of an electrically conducting Carreau fluid due to three geometries (vertical cone, wedge and plate). The coordinate system is considered in such a way that $x$ measures the surface of the body, $y$ measures the normally outward to it. A uniform transverse magnetic field of strength. $B_{0}$ is applied perpendicular to the surface of the geometries as depicted in Fig. 1. It is supposed that $\Omega$ is the wedge full angle, $\gamma$ is the cone or wedge half angle and $r$ is radius of the cone. The temperature $\theta$ and concentration $\phi$ near and far away from the surface is considered as $T_{w}, T_{\infty}$ and $C_{w}, C_{\infty}$ respectively. Cattaneo-Christov heat flux, thermal radiation, thermophoresis, chemical reaction and Brownian motion possessions are taken into account.

Under Boussinesq approximation, the governing boundary layer equations in terms of similarity variable $\xi$ such that $u=$ $\xi_{y}$ and $v=-\xi_{x}$ can be written as

$$
\left.\begin{array}{l}
\frac{\partial}{\partial x}\left(r^{m} \frac{\partial \xi}{\partial y}\right)-\frac{\partial}{\partial y}\left(r^{m} \frac{\partial \xi}{\partial x}\right)=0, \\
\frac{\partial \xi}{\partial y} \frac{\partial^{2} \xi}{\partial x \partial y}-\frac{\partial \xi}{\partial x} \frac{\partial^{2} \xi}{\partial y^{2}}=v\left(\frac{\partial^{3} \xi}{\partial y^{3}}+\frac{3(n-1)}{2} \Gamma^{2}\left(\frac{\partial^{2} \xi}{\partial y^{2}}\right) \frac{\partial^{3} \xi}{\partial y^{3}}\right)+\left(g \beta_{T}\left(T-T_{\infty}\right)+g \beta_{c}\left(C-C_{\infty}\right)\right) \cos \gamma-\frac{\sigma B_{0}^{2}}{\rho} \frac{\partial \xi}{\partial y}, \\
\left.\frac{\partial \xi}{\partial y} \frac{\partial T}{\partial x}-\frac{\partial \xi}{\partial x} \frac{\partial T}{\partial y}+\delta\left(\begin{array}{c}
\left.\frac{\partial \xi}{\partial y} \frac{\partial^{2} \xi}{\partial x \partial y} \frac{\partial T}{\partial x}+\frac{\partial \xi}{\partial x} \frac{\partial^{2} \xi}{\partial y \partial x} \frac{\partial T}{\partial y}-\frac{\partial \xi}{\partial x} \frac{\partial^{2} \xi}{\partial y^{2}} \frac{\partial T}{\partial x}\right)=\left(\frac{k \xi}{\partial y} \frac{\partial \xi}{\partial x}+\frac{\partial^{2} T}{\partial x \partial y}+\left(\frac{\partial \xi}{\partial y}\right)^{2} \frac{\partial^{2} T}{\partial x^{2}}+\left(\frac{\partial \xi}{\partial k^{*}} T^{3}\right.\right. \\
\frac{\partial}{\partial x}
\end{array}\right) \frac{\partial^{2} T}{\partial y^{2}}\right) \\
+\tau\left(y^{2}\right. \\
\left.D_{B} \frac{\partial C}{\partial y} \frac{\partial T}{\partial y}+\frac{D_{B}}{T_{\infty}}\left(\frac{\partial T}{\partial y}\right)^{2}\right),
\end{array}\right\}
$$

$\frac{\partial \xi}{\partial y} \frac{\partial C}{\partial x}-\frac{\partial \xi}{\partial x} \frac{\partial C}{\partial y}=D_{m} \frac{\partial^{2} C}{\partial y^{2}}+\frac{D_{T}}{T_{\infty}} \frac{\partial^{2} T}{\partial y^{2}}-k_{l}\left(C-C_{\infty}\right)$

The corresponding boundary conditions are

$$
\begin{aligned}
& u(x, 0)=u_{w}=v x / l^{2}, v(x, 0)=0, \\
& -k_{f} \frac{\partial T(x, 0)}{\partial y}=h_{f}\left(T_{w}-T_{\infty}\right),-k_{f} \frac{\partial C(x, 0)}{\partial y}=h_{f}\left(C_{w}-C_{\infty}\right), \\
& u(x, \infty)=0, T(x, \infty)=T_{\infty}, C(x, \infty)=C_{\infty},
\end{aligned}
$$

The proposed problem shows three-different geometries based on the following assumptions:

$$
\begin{aligned}
& m=0 \text { and } \gamma \neq 0 \text { corresponds to flow over a } \\
& \text { vertical wedge. } \\
& m=1 \text { and } \gamma \neq 0 \text { corresponds to flow over a } \\
& \text { vertical cone. } \\
& m=0 \text { and } \gamma=0 \text { corresponds to flow over a } \\
& \text { vertical plate. }
\end{aligned}
$$

where the velocity components along $x$ and $y$ directions are $u$ and $v$ respectively. $\sigma$ is the electrical conductivity, $v$ is the kinematic viscosity, $B_{0}$ is the applied magnetic field strength, $\rho$ is the density of the fluid, $\delta$ is the relaxation time of heat flux, $g$ is acceleration due to gravity, $k$ is the thermal conductivity, $\beta_{T}$ and $\beta_{C}$ are the volumetric thermal and concentration expansion coefficients, $c_{p}$ is the specific heat at constant pressure, $D_{B}$ is the Brownian motion coefficient, $D_{T}$ is the thermophoresis coefficient, $k_{l}$ is the chemical reaction, $\sigma^{*}$ is the Stefan-Boltzmann constant, $k^{*}$ is the mean absorption coefficient and $l$ is the characteristic length.

We now introduce the similarity transforms as 
$\zeta=\frac{y}{l}, u=\frac{v x}{l^{2}} \frac{\partial f}{\partial \zeta}, v=\frac{-v(m+1)}{l} f(\zeta)$,

$T=T_{\infty}+\left(T_{w}-T_{\infty}\right) \theta(\zeta), C=C_{\infty}+\left(\mathrm{C}_{w}-C_{\infty}\right) \phi(\zeta)$,

Now substituting the above similarity transformations in Eqs. (1) - (4), gives

$\frac{\partial^{3} f}{\partial \zeta^{3}}+\frac{3(n-1)}{2}\left(\frac{\partial^{2} f}{\partial \zeta^{2}}\right)^{2} W e \frac{\partial^{3} f}{\partial \zeta^{3}}+(m+1) f \frac{\partial^{2} f}{\partial \zeta^{2}}-\left(\frac{\partial f}{\partial \zeta}\right)^{2}-M \frac{\partial f}{\partial \zeta}+(G r \theta+G c \phi) \cos \gamma=0$,

$\left(\frac{1}{\operatorname{Pr}}+\frac{4}{3} \frac{N r}{\operatorname{Pr}}\right) \frac{\partial^{2} \theta}{\partial \zeta^{2}}+(m+1) f \frac{\partial \theta}{\partial \zeta}-(m+1)^{2} \beta_{1}\left(\frac{\partial f}{\partial \zeta} \frac{\partial \theta}{\partial \zeta}+f^{2} \frac{\partial^{2} \theta}{\partial \zeta^{2}}\right)+N t\left(\frac{\partial \theta}{\partial \zeta}\right)^{2}+N b \frac{\partial \theta}{\partial \zeta} \frac{\partial \phi}{\partial \zeta}=0$,

$\frac{1}{L e} \frac{\partial^{2} \phi}{\partial \zeta^{2}}+\left((m+1) f \frac{\partial \phi}{\partial \zeta}-K r \phi\right)+\frac{N t}{N b} \frac{\partial^{2} \theta}{\partial \zeta^{2}}=0$,

The corresponding boundary conditions are

$$
\left.\begin{array}{l}
f=0, \frac{\partial f}{\partial \zeta}=1, \frac{\partial \theta}{\partial \zeta}=-B i_{1}(1-\theta(\varsigma)), \frac{\partial \phi}{\partial \zeta}=-B i_{2}(1-\phi(\varsigma)), \text { at } \zeta=0, \\
\frac{\partial f}{\partial \zeta}=0, \theta=0, \phi=0 \quad \text { as } \zeta \rightarrow \infty,
\end{array}\right\}
$$

where $W e$ is the weissenberg number, $n$ is the velocity power-law index, $M$ is the magnetic field parameter, $G r$ is the thermal Grashof number, $G c$ is the mass Grashof number, $\operatorname{Pr}$ is the Prandtl number, $\beta_{1}$ is the thermal relaxation parameter, $N r$ is the radiation parameter, $L e$ is the Lewis number, $K r$ is the chemical reaction parameter, $B i_{1}$ is the thermal Biot number, $B i_{2}$ is the concentration biot number, $N b$ is the Brownian motion parameter and $N t$ is the thermophoresis parameter which are defined as,

$\left.\begin{array}{l}W e=\frac{\Gamma^{2} v x^{2}}{l^{2}}, M=\frac{\sigma_{0} B_{0}^{2} l^{2}}{\rho v}, G r=\frac{l^{2} g \beta_{T}\left(T_{w}-T_{\infty}\right)}{v u_{w}}, G c=\frac{l^{2} g \beta_{C}\left(C_{w}-C_{\infty}\right)}{v u_{w}}, \operatorname{Pr}=\frac{\mu c_{p}}{k}, L e=\frac{v}{D_{B}}, B i_{1}=\frac{h_{f} l}{k_{f}} \\ N b=\frac{D_{B} \tau\left(C_{w}-C_{\infty}\right)}{v}, N t=\frac{D_{T} \tau\left(T_{w}-T_{\infty}\right)}{v T_{\infty}}, N r=\frac{4 \sigma^{*} T_{\infty}^{3}}{k k^{*}}, \tau=\frac{\left(\rho c_{P}\right)_{p}}{\left(\rho c_{P}\right)_{f}}, \beta_{1}=\frac{\delta v}{l^{2}}, K r=\frac{k l^{2}}{v}, B i_{2}=\frac{h_{f} l}{k_{f}}\end{array}\right\}$

For engineering interest, the friction factor $\left(C_{f}\right)$, local Nusselt number $(\mathrm{Nu})$ and local Sherwood number $(\mathrm{Sh})$ are given by

$$
\begin{aligned}
& C_{f}=\frac{C_{f}^{*}}{\mu u_{w}}=f^{\prime \prime}(0), \\
& N u=\frac{h l}{k\left(T_{w}-T_{\infty}\right)}=-\theta^{\prime}(0), S h=\frac{h_{m} l}{\left(C_{w}-C_{\infty}\right)}=-\phi^{\prime}(0),
\end{aligned}
$$

where $C_{f}{ }^{*}$ is the dimensional wall shear stress.

\section{METHOD OF SOLUTION}

$\mathrm{T}$ The nonlinear differential equations (ODEs) (7), (8) and (9) with the boundary constraints (10) are solved numerically using Runge-Kutta Feldberg method. Initially, the set of nonlinear ODEs converted to $1^{\text {st }}$ order differential equations, by using the following process: $\frac{\partial f}{\partial \zeta}=y 2, \frac{\partial^{2} f}{\partial \zeta^{2}}=y 3, \frac{\partial \theta}{\partial \zeta}=y 5, f=y 1, \theta=y 4, \phi=y 6, \frac{\partial \phi}{\partial \zeta}=y 7$,

$y_{3}^{\prime}=\frac{1}{\left(1+\frac{3(n-1)}{2} y_{3}^{2} W e\right)}\left((m+1) y_{1} y_{3}+y_{2}^{2}+M y_{2}-\left(G r y_{4}+G c y_{6}\right) \cos \gamma\right)$,

$y_{5}{ }^{\prime}=\frac{1}{\left(\left(\frac{1}{\operatorname{Pr}}+\frac{4}{3} \frac{R}{\operatorname{Pr}}\right)+(m+1)^{2} \beta_{1} y_{1}^{2}\right)^{2}}\left(-(m+1) y_{1} y_{5}+(m+1)^{2} \beta_{1} y_{2} y_{5}-N t y_{5}^{2}-N b y_{5} y_{7}\right)$,

$y_{7}{ }^{\prime}=L e\left(-(m+1) y_{1} y_{7}+K r y_{6}\right)-L e \frac{N t}{N b} y_{5}{ }^{\prime}$

With boundary conditions as

$y 1=y 2=0, y_{5}=-B i_{1}(1-y 4), y_{7}=-B i_{2}(1-y 6)$, at $\eta \rightarrow 0$

$\mathrm{y}_{2}=0, y_{4}=0, y_{6}=0$ at $\eta \rightarrow \infty$

We guess the values of $y_{3}(0), y_{5}(0), y_{7}(0)$ which are not given at the initial conditions. The equations (14)-(16) are integrated by taking the help of Runge-Kutta Feldberg method with the successive iterative step length is 0.01 . For this we used ODE45 MATLAB solver to solve the first order nonlinear coupled differential equations. The correctness of the supposed values is checked by equating the calculated values $y_{2}, y_{4}, y_{6}, y_{8}$ at $\zeta=\zeta_{\max }$ with their given values at $\zeta=$ $\zeta_{\max }$. If there is any difference exist the process is continued up to the required good values. Alternatively, we are using the Runge-Kutta Feldberg method to get the accurately found the initial values of $y_{3}(0), y_{5}(0), y_{7}(0)$ and then integrate Eq. (13)-(16) by using the Runge-Kutta Feldberg method. This process is repeated until the settlement between the designed value and the condition given at is within the specified degree of accuracy $10^{-5}$. In order to validates the precision of the present solutions with Addul Aziz [26] solutions. We found worthy agreement with Aziz [26] solutions under limited case.

\section{RESULTS AND DISCUSSION}

The non-dimensional governing equations (7)-(9) and subject to the respective boundary conditions (10) are solved numerically using Runge-Kutta Feldberg method.In order to exploring the results, the numerical solutions are found for various values of non-dimensional governing parameters on the flow, mass and heat transfer characteristics of nanofluiddue to cone/plate and wedge with CatterneoChristov heat flux model. For numerical computations we considered the non-dimensional values $L e=1, M=0.5, \beta_{1}=$ $W e=0.2, N t=0.2, N b=0.3, P r=4, n=2, N r=$ $0.5, B i=G r=G c=K r=0.2$. These values are preserved as common in the entire examination except the different values are displayed in specific figures and tables. In this analysis, solid lines designate the flow due to plate, dashed lines designate the flow due to wedge and dotted lines designate the flow due to cone. Figs. 2-19 display the variations of velocity $\left(f^{\prime}\right)$, temperature $(\theta)$ and concentration ( $\phi)$ fields for varied values of $N t, N b, M, B i, K r, \beta_{1}, G r, G c$ and $N r$ respectively. Figs. 2 and 
3 are plotted to investigate the impact of thermophoresis parameter $(N t)$ on temperature $(\theta)$ and concentration fields for the three cases plate, wedge and cone cases. The rising values of $N t$ increase the temperature $(\theta)$ as well as concentration $(\phi)$ fields. This fact indicates that the diffusion of nanoparticles is high due to the domination of thermophoresis parameter.

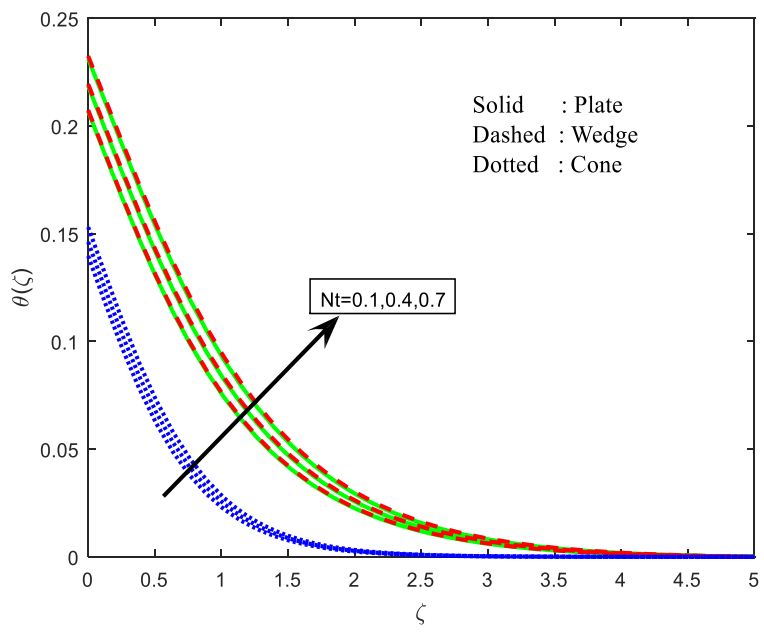

Figure 2. The effect of $N t$ on temperature field

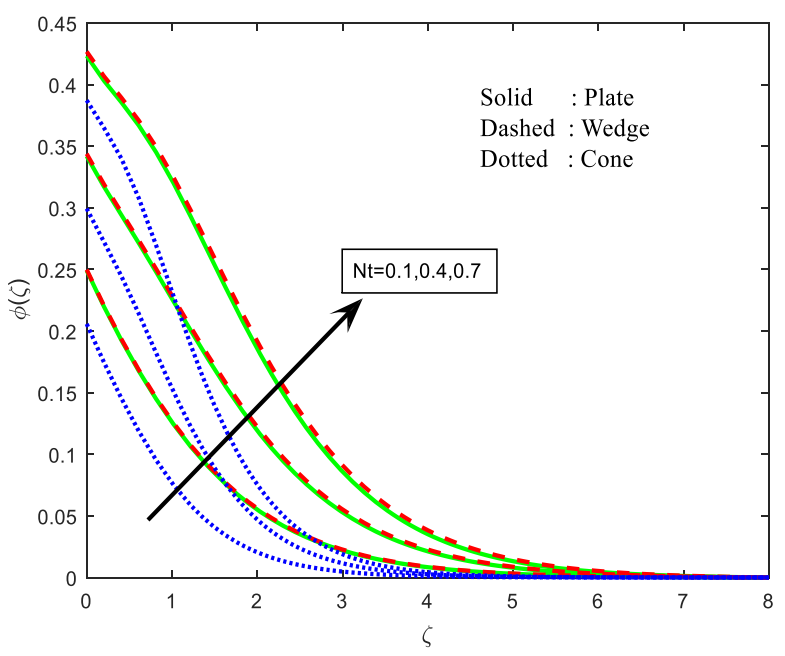

Figure 3. The impact of $N t$ on concentration field

Figs. 4 and 5 illustrate the effect of $\mathrm{Nb}$ on the temperature $(\theta)$ and concentration fields. It is obvious that $\theta(\zeta)$ is encouraged and concentration field is depreciated with the rising values of $N b$. Due to the different particles have different values of $N b$. It is found that the influence of $N b$ is very less in cone when compared with wedge and plate due to domination of buoyancy force. The growing values of Biot number $(B i)$ improve the velocity $\left(f^{\prime}\right)$, temperature $(\theta)$ and concentration fields. This may occur due to domination of mixed convection, which can help to encourages the velocity $\left(f^{\prime}\right)$, temperature $(\theta)$ and concentration fields. These are displayed in Figs. 6-8. The thermal radiation $(\mathrm{Nr})$ lifts up the temperature field $(\theta)$ and shows mixed performance in concentration field $(\phi)$. This approves the common behavior of thermal radiation $(N r)$. These graphs are designed in Fig. 9 and 10. The heat generation is lesser in cone when compared with plate and wedge. The impact of chemical reaction $(K r)$ parameter on concentration profiles is plotted in Fig. 11. It specifies that the climbing values of chemical reaction parameter $(K r)$ depreciate the concentration field for all three cases. Generally, an increasing value of $K r$ improves the interfacial mass transfer this helps to depreciate the concentration field. Fig. 12 and 13indicates the effect of $\beta_{1}$ on temperature $(\theta)$ and concentration $(\phi)$ profiles. It is noted that the thermal relaxation parameter $\beta_{1}$ boost up the temperature profiles $(\theta)$ and mixed performance was observed in concentration fields. This may happen due to domination of neighboring particles are activated fast; this can help to improve the temperature field. The domination of resistive type drag force in the flow we have perceived decrement in velocity $\left(f^{\prime}\right)$ and improvement in temperature $(\theta)$ and concentration $(\phi)$ fields with growing values of $M$. These are plotted in Figs. 14-16. It is also found the retarding force is high in plate when compared with cone and wedge. The effect of We on velocity $\left(f^{\prime}\right)$, temperature $(\theta)$ and concentration $(\phi)$ profiles are revealed in Figs. 17-19. Noted from that the developing values of Weissenberg number improves $f^{\prime}(\zeta)$ and reduces $\theta(\zeta), \phi(\zeta)$ profiles. Generally higher values of $W e$ keeps more pressure on the flow, this can lead to improve the velocity field and reduces the temperature profiles.

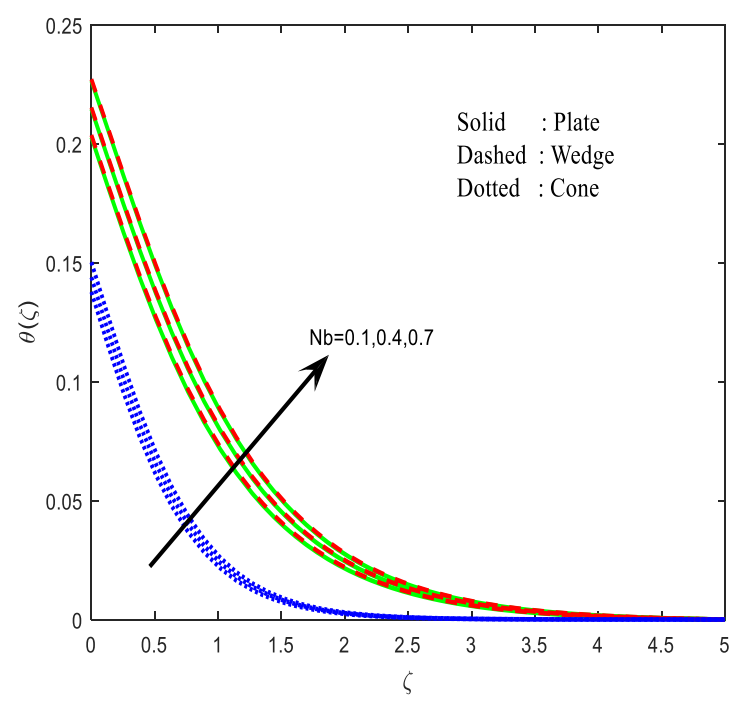

Figure 4. The effect of $\mathrm{Nb}$ on temperature field

From Figs 20-25 displays the deviations in the rate of heat $\left(-\theta^{\prime}(0)\right)$ and mass transfer $\left(-\phi^{\prime}(0)\right)$ for the flow over a cone/plate/wedge cases with varied values of different nondimensional governing parameters. From Fig. 20 and 21 reveals the effect of chemical reaction $(K r)$, Brownian motion $(N b)$ and thermophoresis $(N t)$ on local Nusselt number for three cases. The increasing values of $K r a n d N b$ improves the Local Nusselt $\left(-\theta^{\prime}(0)\right)$ and Sherwood number $\left(-\phi^{\prime}(0)\right)$. But the thermophoresis parameter reduces the Local Sherwood number and encourages the local Nusselt number. Due to higher particle to particle interaction in cone the heat transfer rate $\left(-\theta^{\prime}(0)\right)$ is high. The influence of $N r, \beta_{1}$ and $M$ is plotted in Figs. 2223. The rate of heat $\left(-\theta^{\prime}(0)\right)$ and mass transfer $\left(-\phi^{\prime}(0)\right)$ is enhanced with thermal radiation ${ }^{(N r)}$ and depreciated with magnetic field. The thermal relaxation parameter increases 
the mass transfer rate and minimizes the heat transfer rate. The rising values of $W e$ slightly increases in local Nusselt $\left(-\theta^{\prime}(0)\right)$ and Sherwood numbers $\left.\left(-\phi^{\prime}(0)\right)\right)$ for the flow over three geometries, whereas, the Biot number $(B i)$ enhancing the rate of heat and mass transfer $\left(\left(-\theta^{\prime}(0),-\phi^{\prime}(0)\right)\right.$. These plots are displayed in Figures 24 and 25. The rate of heat transfer $\left(-\theta^{\prime}(0)\right)$ is higher in cone due to the domination higher pressure forces in the flow. From these results we can determine that for improving the heat transfer rate $\left(-\theta^{\prime}(0)\right)$ the cone shaped particles are helpful Table 1 shows the deviations of friction factor coefficient with various values of governing parameter for flow over three cases. The boosting values of thermal relaxation parameter $\left(\beta_{1}\right)$, thermophoresis parameter $(\mathrm{Nt})$, thermal radiation $(\mathrm{Nr})$, Weissenberg number $(W e)$ and Biot numbers $(B i)$ are encourages the friction factor coefficient for the three cases. The Brownian motion, chemical reaction $(\mathrm{Kr})$ and magnetic field parameters are reduces the skin friction coefficient. Table 2 display the justification of current solutions with existing studies under some limited case. We found that the growing values of Biimproves local Nusselt number.

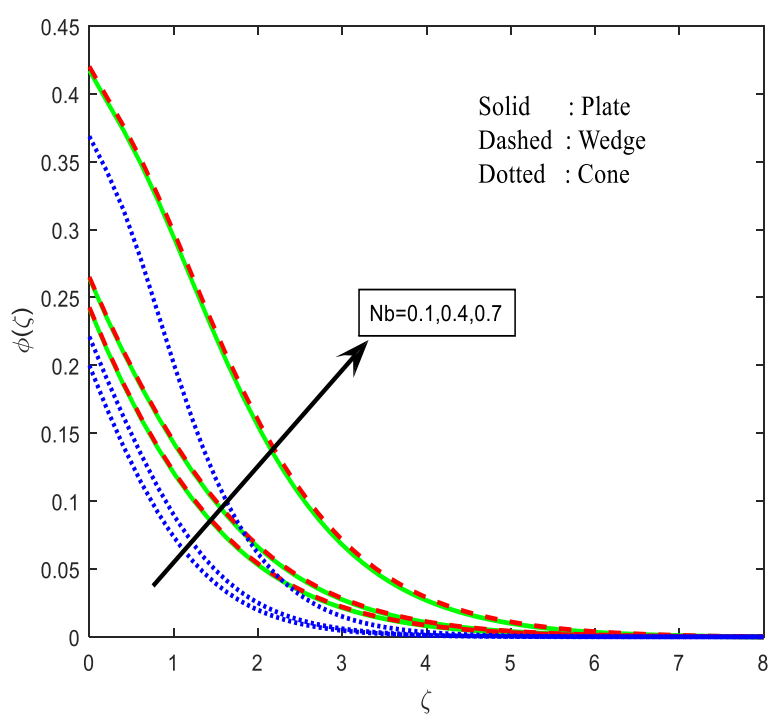

Figure 5. The impact of $N b$ on concentration field

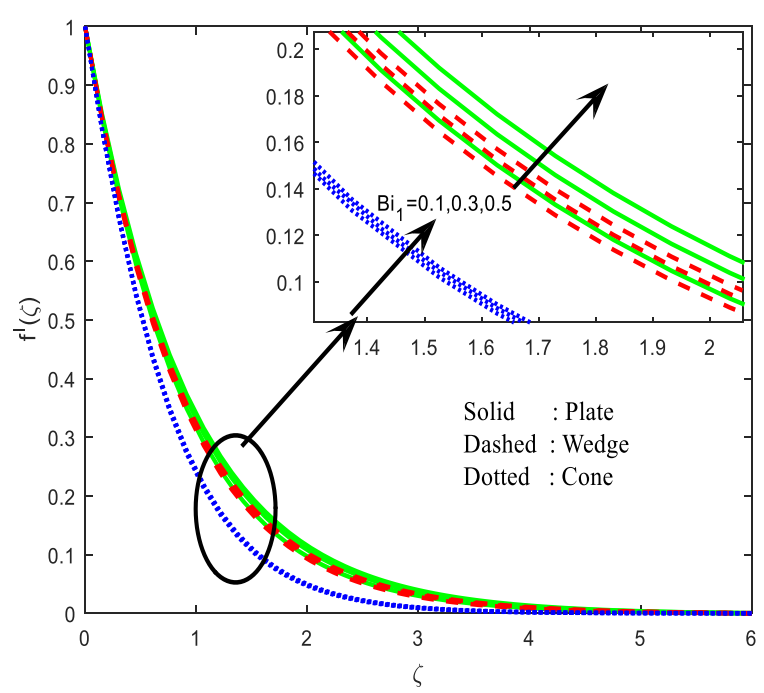

Figure 6. The influence of $B i_{1}$ on velocity field

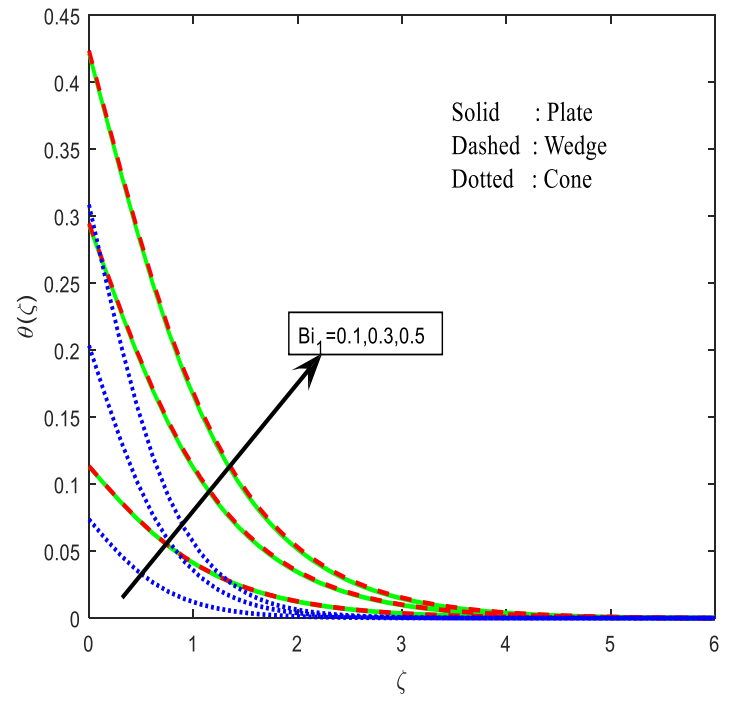

Figure 7. The impact of $B i_{1}$ on temperature field

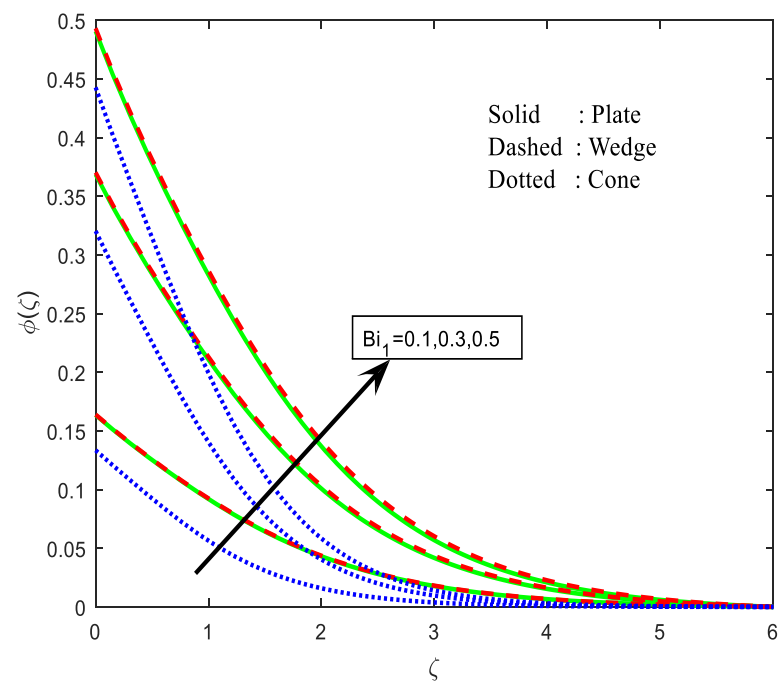

Figure 8. The effect of $B i_{1}$ on concentration field

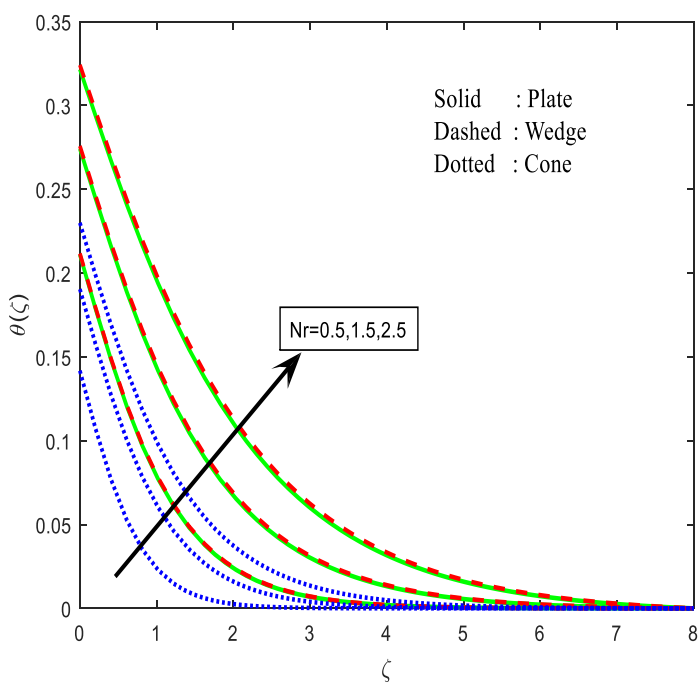

Figure 9. The impact of $N r$ on temperature field 


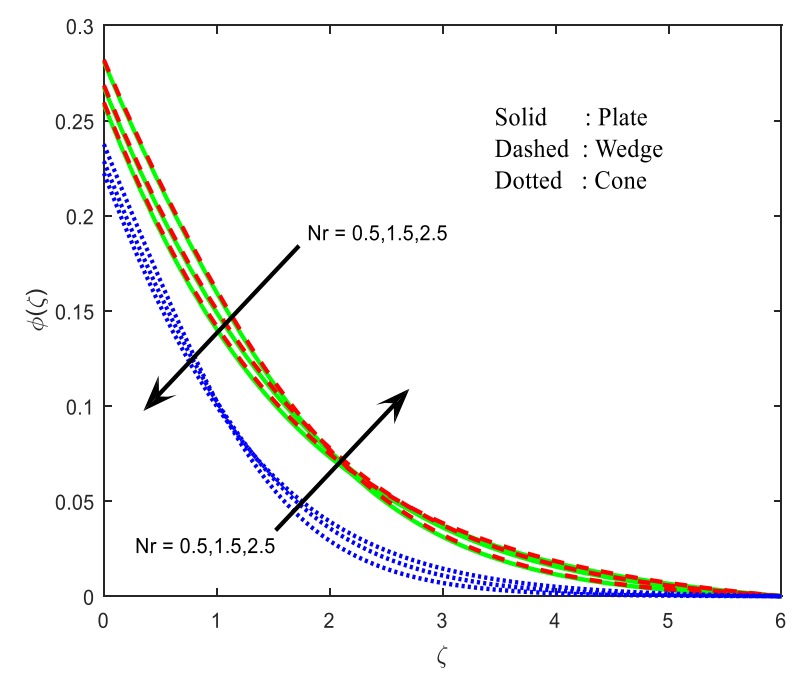

Figure 10. The impact of $\mathrm{Nr}$ on concentration field

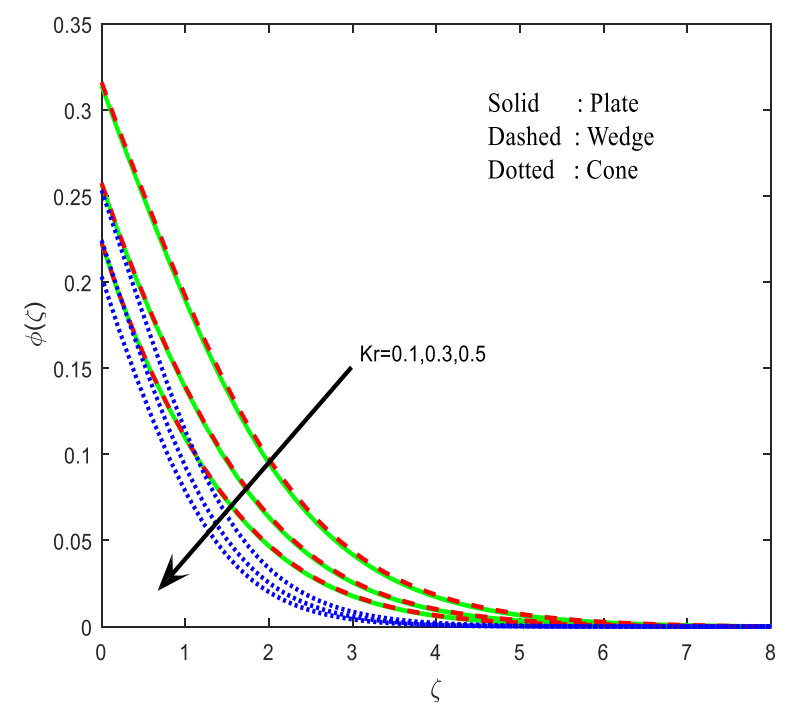

Figure 11. The impact of $K r$ on concentration field

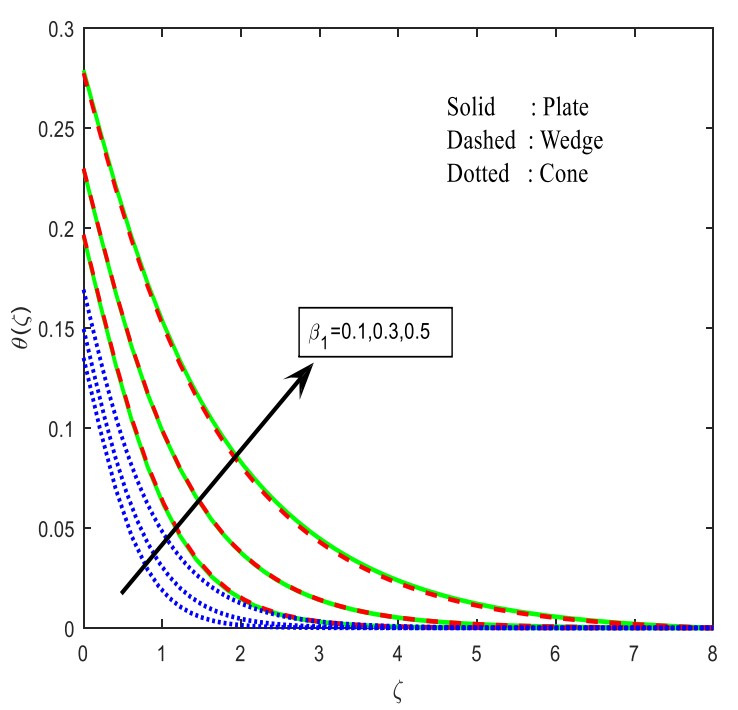

Figure 12. The impact of $\beta_{1}$ on temperature field

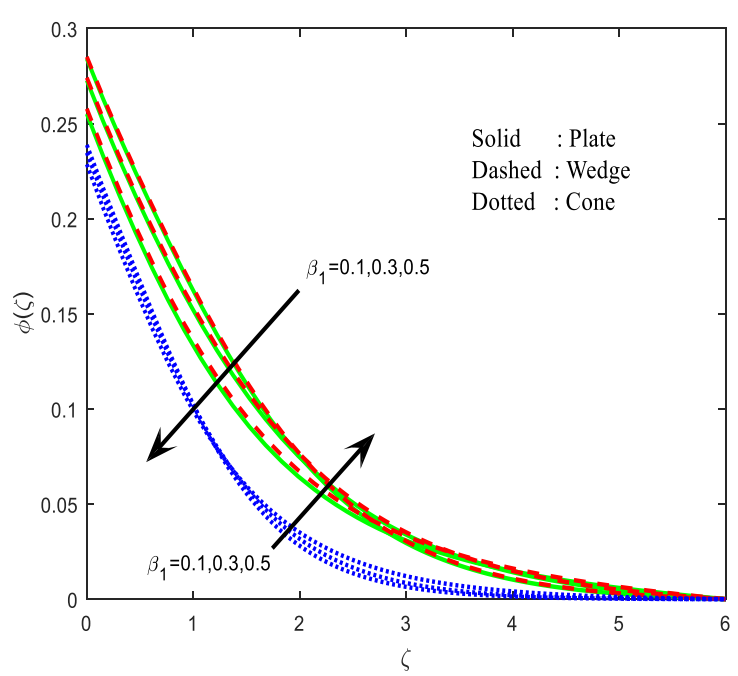

Figure 13. The influence of $\beta_{1}$ on concentration field

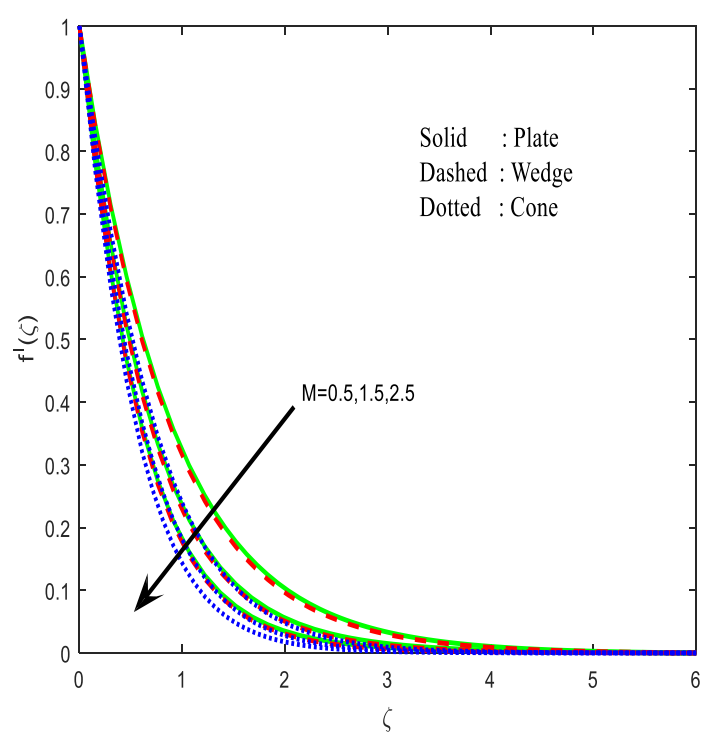

Figure 14. The impact of $M$ on velocity field

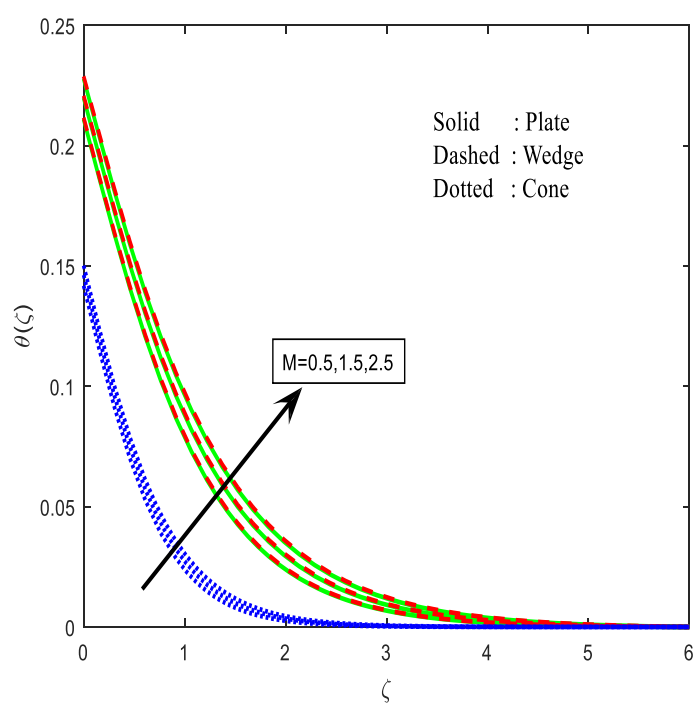

Figure 15. The impact of $M$ on temperature field 


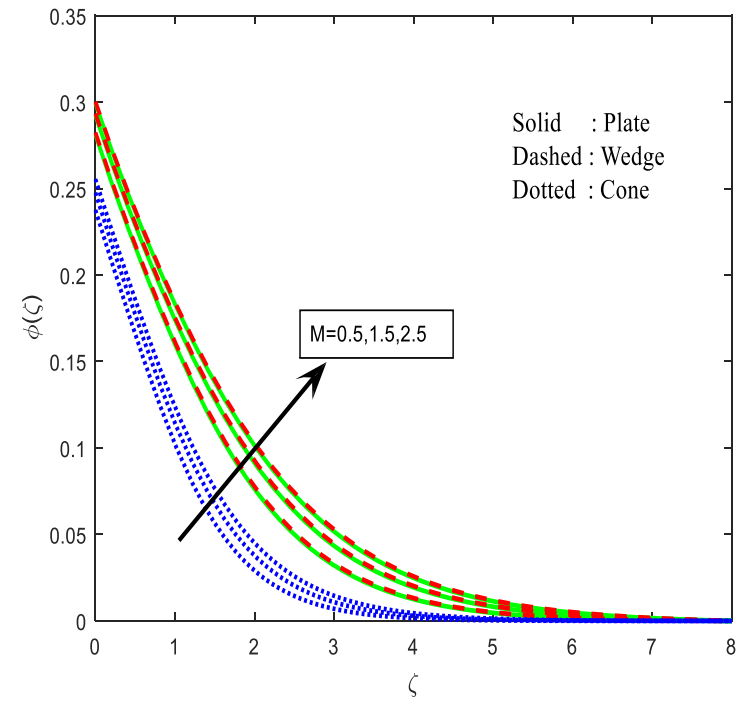

Figure 16. The effect of $M$ on concentration field

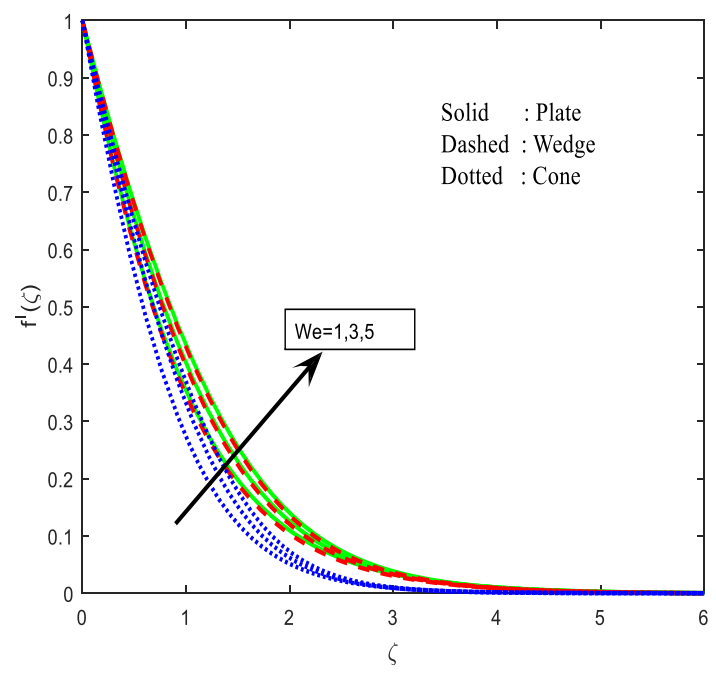

Figure 17. The impact of $W e$ on velocity field

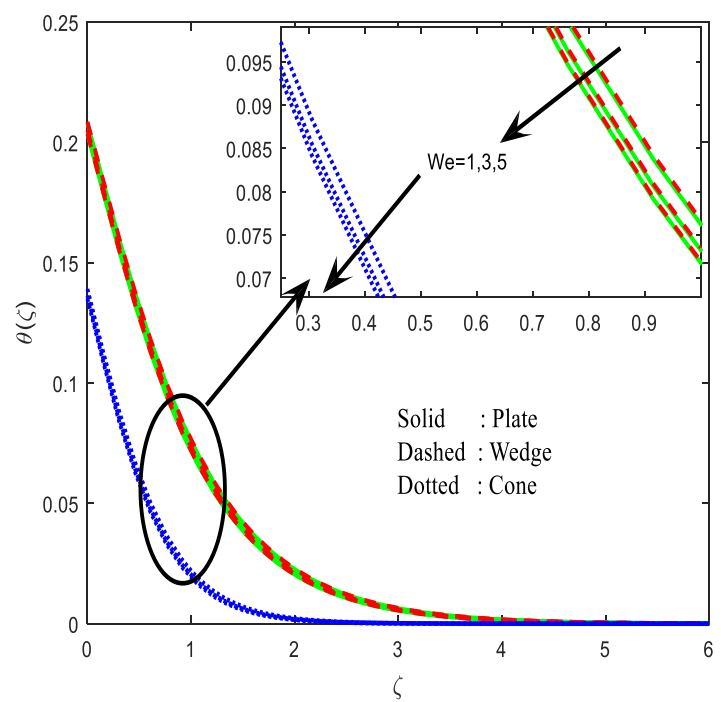

Figure 18. The effect of $W e$ on temperature field

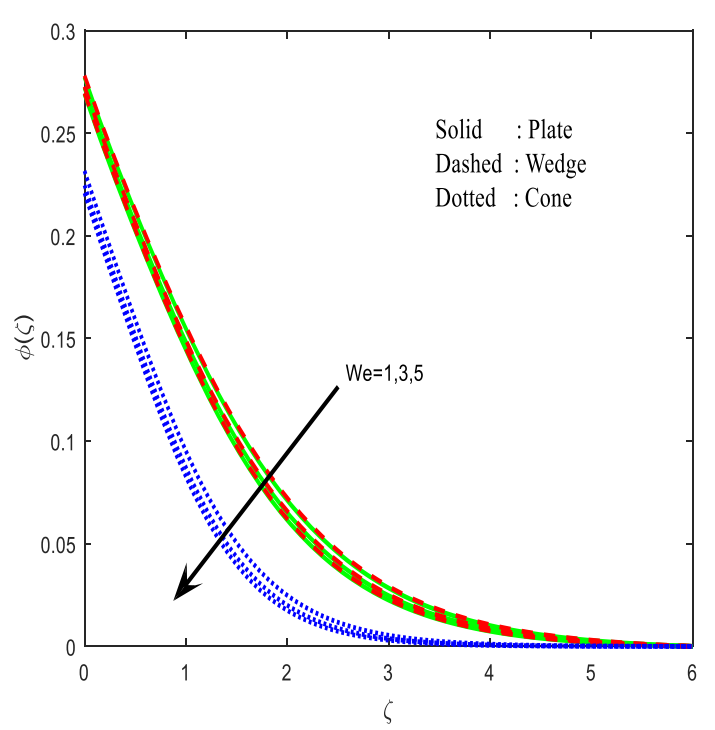

Figure 19. The effect of $W e$ on concentration field

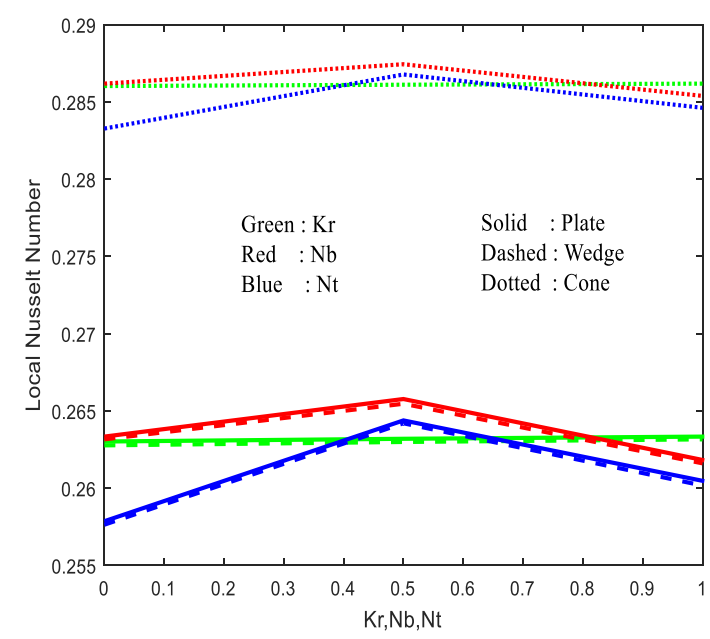

Figure 20. The local Nusselt number for various values of $\mathrm{Kr}, \mathrm{Nb}$ and $\mathrm{Nt}$

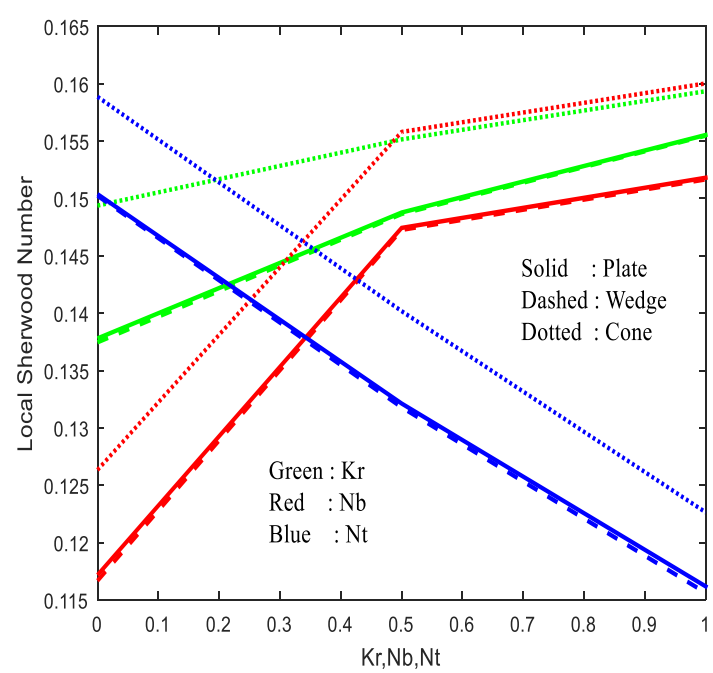

Figure 21. The local Sherwood number for various values of $\mathrm{Kr}, \mathrm{Nb}$ and $\mathrm{Nt}$ 


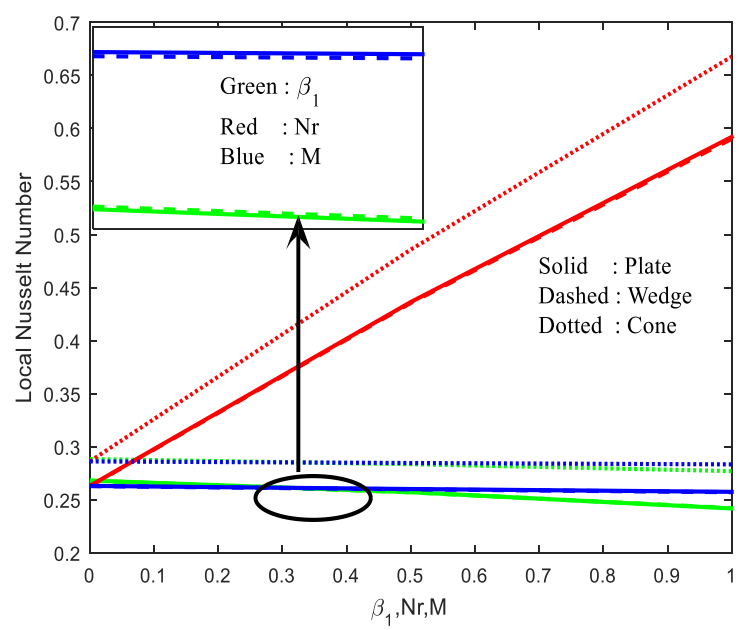

Figure 22. The local Nusselt number for various values of $\beta_{1}, N r$ and $M$

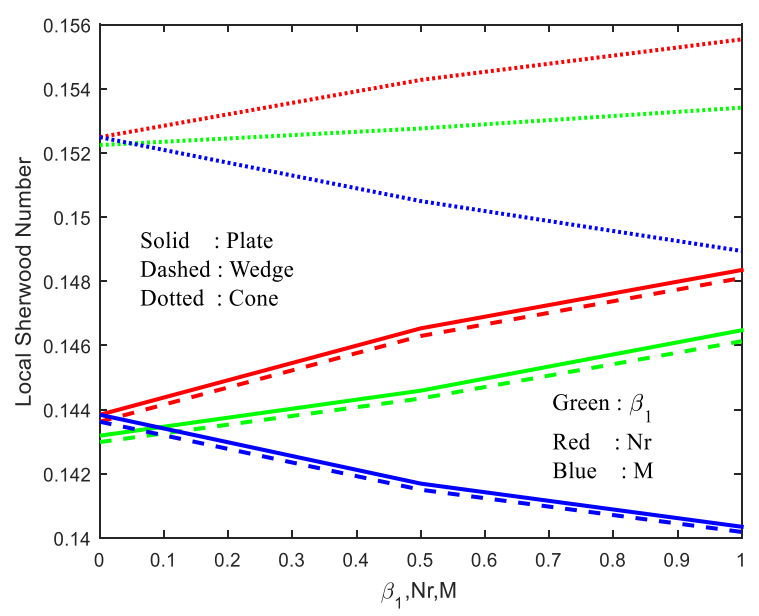

Figure 23. The local Sherwood number for various values of $\beta_{1}, N r$ and $M$

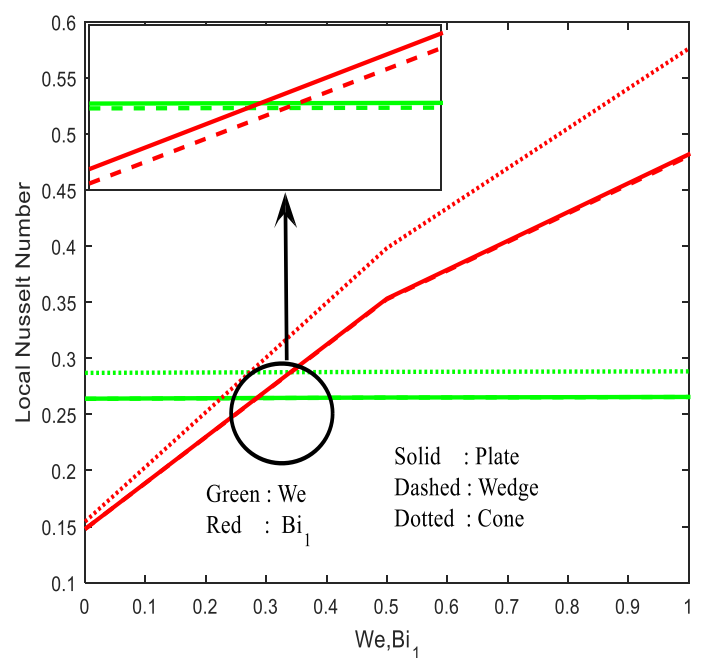

Figure 24. The local Nusselt number for various values of $W e$ and $B i_{1}$
Table 1. Variations in friction factor coefficient for cone, wedge and plate cases

\begin{tabular}{|c|c|c|c|c|c|c|c|c|c|c|c|}
\hline \multirow[t]{2}{*}{$\mathrm{Kr}$} & \multirow[t]{2}{*}{$\mathrm{Nb}$} & \multirow[t]{2}{*}{$\mathrm{Nt}$} & \multirow[t]{2}{*}{$\beta$} & \multirow[t]{2}{*}{$N_{r}$} & \multirow[t]{2}{*}{$M$} & \multirow[t]{2}{*}{ We } & \multirow[t]{2}{*}{$B i$} & \multirow{2}{*}{$B i_{2}$} & \multicolumn{3}{|c|}{ Skin fiction coefficient } \\
\hline & & & & & & & & & Plate & Wedge & Cone \\
\hline 0.1 & & & & & & & & & -1.081939 & -1.104009 & -1.226816 \\
\hline 0.3 & & & & & & & & & -1.088784 & -1.107524 & -1.228277 \\
\hline 0.5 & & & & & & & & & -1.092876 & -1.109601 & -1.229311 \\
\hline & 0.1 & & & & & & & & -1.069018 & -1.097450 & -1.221053 \\
\hline & 0.4 & & & & & & & & -1.087703 & -1.106964 & -1.228385 \\
\hline & 0.7 & & & & & & & & -1.089378 & -1.107814 & -1.22924 \\
\hline & & 0.1 & & & & & & & -1.090614 & -1.108439 & -1.229374 \\
\hline & & 0.4 & & & & & & & -1.076573 & -1.101905 & -1.224113 \\
\hline & & 0.3 & & & & & & & -1.063226 & -1.094471 & -1.218895 \\
\hline & & & 0.1 & & & & & & -1.087186 & -1.106626 & -1.227894 \\
\hline & & & 0.3 & & & & & & -1.083202 & -1.104642 & -1.227170 \\
\hline & & & 0.5 & & & & & & -1.077224 & -1.101730 & -1.226082 \\
\hline & & & & 0.5 & & & & & -1.085403 & -1.105735 & -1.227567 \\
\hline & & & & 1.5 & & & & & -1.078043 & -1.101970 & -1.225116 \\
\hline & & & & 2.5 & & & & & -1.072317 & -1.099031 & -1.22279 \\
\hline & & & & & 0.5 & & & & -1.085403 & -1.105735 & -1.227567 \\
\hline & & & & & 1.5 & & & & -1.361363 & -1.378111 & -1.464700 \\
\hline & & & & & 2.5 & & & & -1.566741 & -1.581062 & -1.649482 \\
\hline & & & & & & 1 & & & -0.927119 & -0.040452 & -1.029243 \\
\hline & & & & & & 3 & & & -0.780732 & -0.789602 & -0.857763 \\
\hline & & & & & & 5 & & & -0.710848 & -0.718018 & -0.778026 \\
\hline & & & & & & & 0.1 & & -1.103409 & -1.114811 & -1.233125 \\
\hline & & & & & & & 0.3 & & -1.070993 & -1.098454 & -1.222855 \\
\hline & & & & & & & 0.5 & & -1.049593 & -1.087635 & -1.215350 \\
\hline & & & & & & & & 0.1 & -1.092244 & -1.109166 & -1.229839 \\
\hline & & & & & & & & 0.3 & -1.079568 & -1.10277 & -1.225636 \\
\hline & & & & & & & & 0.5 & -1.070971 & -1.098435 & -1.222578 \\
\hline
\end{tabular}

Table 2. The Validation of the present results with already existed literature some limited case

\begin{tabular}{|l|l|l|l|l|l|l|l|l|}
\hline & \multicolumn{5}{|c|}{$\operatorname{Pr}=0.1$} & \multicolumn{5}{c|}{$\operatorname{Pr}=0.72$} \\
\hline $\begin{array}{l}B i \\
\downarrow\end{array}$ & $\begin{array}{l}\theta(0) \\
\text { Abdul }\end{array}$ & $\begin{array}{l}-\theta^{\prime}(0) \\
\text { Abdul } \\
\text { Azziz } \\
\text { Azziz [26] }\end{array}$ & $\begin{array}{l}\theta(0) \\
\text { Current } \\
\text { results }\end{array}$ & $\begin{array}{l}-\theta^{\prime}(0) \\
\text { Current } \\
\text { results }\end{array}$ & $\begin{array}{l}\theta(0) \\
\text { Abdul } \\
\text { Aziz } \\
{[26]}\end{array}$ & $\begin{array}{l}-\theta^{\prime}(0) \\
\text { Abdul } \\
\text { Aziz } \\
{[26]}\end{array}$ & $\begin{array}{l}\theta(0) \\
\text { Current } \\
\text { results }\end{array}$ & $\begin{array}{l}-\theta^{\prime}(0) \\
\text { Current } \\
\text { results }\end{array}$ \\
\hline 0.05 & 0.2536 & 0.0373 & 0.2542 & 0.0372 & 0.1447 & 0.0428 & 0.1449 & 0.0426 \\
\hline 0.1 & 0.4046 & 0.0594 & 0.4107 & 0.0596 & 0.2528 & 0.0747 & 0.25278 & 0.0747 \\
\hline 0.2 & 0.5761 & 0.8480 & 0.5762 & 0.8481 & 0.4035 & 0.1193 & 0.40349 & 0.1192 \\
\hline 0.4 & 0.731 & 0.1076 & 0.731 & 0.1076 & 0.5750 & 0.1700 & 0.5750 & 0.1699 \\
\hline
\end{tabular}

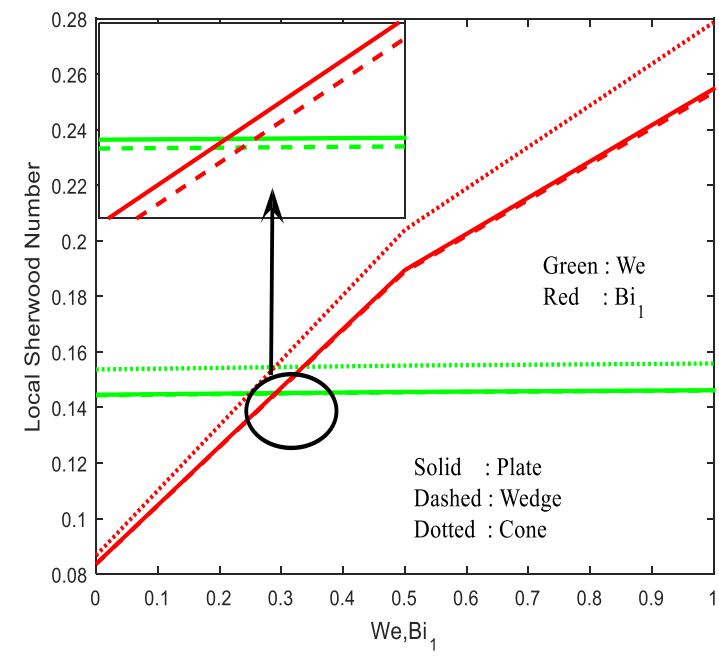

Figure 25. The local Sherwood number for various values of $W e$ and $B i_{1}$ 


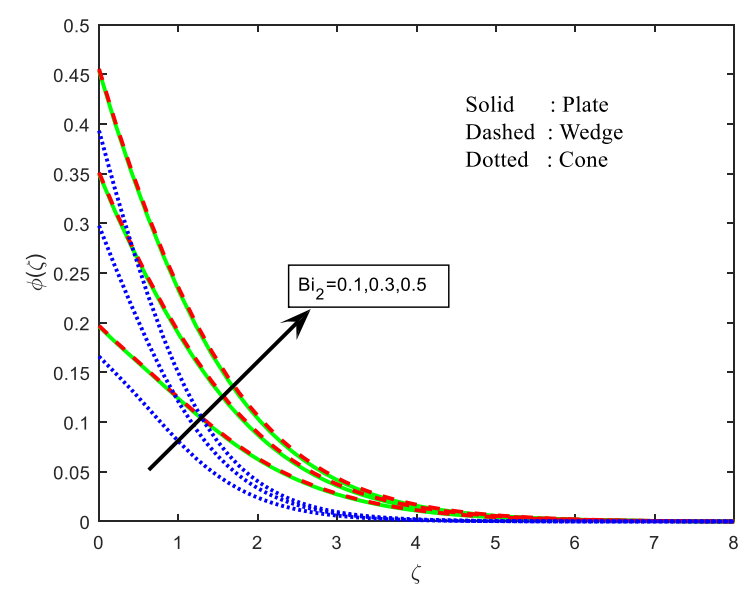

Figure 26. The influence of $B i_{2}$ on concentration field

\section{CONCLUSIONS}

The combined effects of Brownian motioned thermophoresis parameters have many real time applications such as engineering, safety engineering, geo-technological processes. Keeping view into this, Brownian motion and thermophoresis effects on magnetohydrodynamic flow over a cone/plate/wedge is considered. For controlling the heat transfer rate, Cattaneo-Christov heat flux also taken into account. The arising set of coupled nonlinear ODEs is solved numerically Runge-Kutta Feldberg method. We found the velocity, temperature and concentration fields through graphs. For real time interest, we also found the friction factor coefficient, local Nusselt and Sherwood numbers for the three cases. The highlights of this present study are as follows:

- The combined effects of Brownian motion thermophoresis are modulating the mass and heat transfer rates for flow over a cone/wedge/plate. But heat and mass transport phenomena were higher in conewhen compared with wedge and plate cases.

- For minimizing the local Nusselt number thermal relaxation is very helpful.

- The rising values of Biot number advances local Nusselt and Sherwood numbers for cone/plate/wedge cases. From this we can conclude that convection is very helpful for encouraging heat and mass transport processes.

$G r=G c=M=K r=W e=L e=\beta_{1}=\gamma_{2}=m=N r=$ $N b=N t=0$ with different values of Prandtl number.

\section{REFERENCES}

[1] Cattaneo C. (1948). Sullaconduzionedelcalore. Attidel Seminario Matematicoe Fisicodell Universitadi Modenae Reggio Emilia 3: 83-101.

[2] Christov CI. (2009). On frame in different formulation of the Maxwell-Cattaneo model of finite-speed heat conduction. Mech. Res. Commun 36: 481-486.

[3] Straughan B. (2010). Thermal convection with the Cattaneo-Christov model. Int. J. Heat Mass Transfer 53: 95-98.

[4] Han S, Zheng L, Li C, Zhang X. (2014). Coupled flow and heat transfer in viscoelastic fluid with Cattaneo-
Christov heat flux model. Applied Mathematics Letters 38: 87-93. https://doi.org/10.1016/j.aml.2014.07.013

[5] Hayat T, Imtiaz M, Alsaedi A, Almezal S. (2016). On Cattaneo-Christov heat flux in MHD flow of OldroydB fluid with homogeneous-heterogeneous reactions. Journal of Magnetism and Mateirals 401: 296-303.

[6] Rubab K, Mustafa M. (2016). Cattaneo-Christov heat flux model for MHD three-dimensional flow of maxwell fluid over a stretching sheet. Plos One 11: e0153481. https://doi.org/10.1371/journal.pone.0153481

[7] Hayat T, Farooq M, Alsaedi A, Al-solamy F, Hayat T, Farooq M, et al. (2016). Impact of Cattaneo-Christov heat flux in the flow over a stretching sheet with variable thickness. AIP Advances 5, 087159. https://doi.org/10.1063/1.4929523

[8] Salahuddin T, Malik MY, Hussain A, Bilal S, Awais M. (2016). MHD flow of Cattanneo-Christov heat flux model for Williamson fluid over a stretching sheet with variable thickness: Using numerical approach. Journal of Magnetism and Magnetic Materials 401: 991-997. https://doi.org/10.1016/j.jmmm.2015.11.022

[9] Vajravelu K, Nayfeh J. (1992). Hydromagnetic convection at a cone and a wedge, Int. Comm. Heat. Mass Transfer 19: 701-710.

[10] Yu WS, Lin HT, Hwang TY. (1991). Conjugate heat transfer of conduction and forced convection along wedges and a rotating cone. Int. J. Heat. Mass Transfer 34(10): 2497-2507.

[11] Chamkha AJ. (1996). Non-Darcy hydromagnetic free convection from a cone and a wedge in porous media. Int. Comm. Heat Mass Transfer 23(6): 875-887.

[12] Al-Harbi SM. (2005). Numerical study of natural convection heat transfers with variable viscosity and thermal radiation from a cone and wedge in porous media. Applied Mathematics and Computation 170: 6475. https://doi.org/10.1016/j.amc.2004.10.093

[13] Press P. (2008). Conjugate heat transfer of conduction and forced convection along wedges and a rotating cone. Int. J. Heat\& Mass Transfer 34: 2491-2501.

[14] Kumar BR, Sivaraj R. (2013). MHD viscoelastic fluid non-Darcy flow over a vertical cone and a flat plate. International Communications in Heat and Mass Transfer 40: 1-6. https://doi.org/10.1016/j.icheatmasstransfer.2012.10.02 5

[15] Raju CSK, Sandeep N. (2016). Heat and mass transfer in MHD non-Newtonian bio-convection flow over a rotating cone/plate with cross diffusion. Journal of Molecular Liquids 215: 115-126.

[16] Mythili D, Sivaraj R. (2016). Influence of higher order chemical reaction and non-uniform heat source/sink on Casson fluid flow over a vertical cone and flat plate. Journal of Molecular Liquids 216: 466-475. https://doi.org/10.1016/j.molliq.2016.01.072

[17] Srinivasacharya D, Bhuvanavijaya R, Mallikarjuna B. (2015). Dispersion effects on mixed convection over a vertical wavy surface in a porous medium with variable properties. Procedia Engineering 127: 271-278.

[18] Raju CSK, Sandeep N. (2016). Falkner Skan flow of a magnetic Carreau fluid past a wedge in the presence of cross diffusion. European Physical Journal Plus 131: 267.

[19] Rashad AM, Mallikarjuna B, Chamkha AJ, Raju SH. 
(2016). Thermophoresis effect on heat and mass transfer from a rotating cone in a porous medium with thermal radiation. Afrika Matematika 1-16.

[20] Nadeem S, Saleem S. (2015). An optimized study of mixed convection flow of a rotating Jeffrey nanofluid on a rotating vertical cone. J. Computational and Theoretical Nanoscience 12(11): 1-8.

[21] Rashidi MM, Rastegiri MT, Asadi M, Anwar BO. (2012). A study of non-newtonian flow and heat transfer over a non-isothermal wedge using the homotopy analysis method. Chemical Engineering Communications 199: 231-256.

[22] Raju CSK, Sandeep N. (2016). Nonlinear radiative magnetohydrodynamic Falkner-Skan flow of Casson fluid over a wedge. Alexandria Engineering Journal. http://dx.doi.org/10.1016/j.aej.2016.07.006

[23] Hussain SM, Jain J, Seth GS, Rashidi MM. (2017). Free convective heat transfer with hall effects, heat absorption and chemical reaction over an accelerated moving plate in a rotating system. Journal of Magnetism and Magnetic Materials 422: 112-123.

[24] Rashidi MM, Ali M, Freidoonimehr N, Rostami B, Hussain MA. (2014). Mixed convective heat transfer for MHD viscoelastic fluid over porous wedge with thermal radiation. Advances in Mechanical Engineering 2014: 735-939.

[25] Garoosi F, Bagheri G, Rashidi MM. (2015). Two phase simulation of natural convection and mixed convection of the nanofluid in a square cavity. Powder Technology 275: $239-256$

[26] Aziz A. (2009). A similarity solutions for laminar thermal boundary layer over a flat plate with convective conditions. Communications in Nonlinear Sci. Numer. Simil. 14: 1064-1068.

[27] Garoosi F, Rohani B, Rashidi MM. (2015). Two-phase mixture modeling of mixed convection of nanofluis in a square cavity with internal and external heating. Powder Technology 275: 304-321.

[28] Beg OA, Uddin MJ, Rashidi MM, Kavyani N. (2014). Double-diffusive radiative magnetic mixed convective slip flow with Biot and Richardson number effects. J. Engineering Thermophysics 23: 79-97.

[29] Rashidi MM, Ferdows M, Uddin J, Beg O, Rahimzadeh N. (2012). Group theory and differential transform analysis of mixed convective heat and mass transfer from a horizontal surface with chemical reaction effects. Chemical Engineering Communications 199(8): 10121043.

\section{NOMENCLATURE}

\begin{tabular}{|c|c|}
\hline$u, v$ & $\begin{array}{l}\text { Velocity components in } x \text { and } y \text { directions } \\
\text { respectively }(\mathrm{m} / \mathrm{s})\end{array}$ \\
\hline$x$ & Distance along the surface $(m)$ \\
\hline$y$ & Distance normal to the surface $(m)$ \\
\hline$c_{p}, c_{s}$ & $\begin{array}{l}\text { Specific heat capacity at constant pressure } \\
(J / K g K)\end{array}$ \\
\hline$T$ & Temperature of the fluid $(K)$ \\
\hline$C$ & Concentration of the fluid (Moles $/ \mathrm{Kg}$ ) \\
\hline$g$ & Acceleration due to gravity $\left(\mathrm{m} / \mathrm{s}^{2}\right)$ \\
\hline$\alpha_{f}$ & Diffusion coefficient $\left(\mathrm{m}^{2} / \mathrm{s}\right)$ \\
\hline$\left(\rho c_{p}\right)_{f}$ & Heat capacity of the fluid $\left(\mathrm{Kg} / \mathrm{m}^{3} \mathrm{~K}\right)$ \\
\hline
\end{tabular}

\section{Subscripts}

$w \quad$ Condition at the wall

$\infty \quad$ Condition at the free stream 